\title{
A PEDAGOGICAL MODEL TO SCALE UP EFFECTIVE TEACHER PROFESSIONAL DEVELOPMENT - FINDINGS FROM THE TEACHER ACADEMY INITIATIVE OF THE EUROPEAN COMMISSION
}

Benjamin Hertz, European Schoolnet, Hannah Grainger Clemson, European Commission, Belgium, Daniella Tasic Hansen, National Danish Knowledge Centre of e-learning, Denmark, Diana Laurillard, UCL Institute of Education, United Kingdom, Madeleine Murray, PDST Technology in Education, Ireland, Luis Fernandes, Agrupamento de Escolas de Freixo, Portugal, Anne Gilleran, European Schoolnet, Belgium,

Diego Rojas Ruiz, National Institute of Educational Technologies and Teacher Training, Spain, Danguole Rutkauskiene, Kaunas University of Technology, Lithuania

\section{Abstract}

Teachers continue to experience change in education policy, societal trends, and cultural shifts in pedagogical thought, which all require a continual adaptation and innovation of their own practice. Effective support and opportunities for teachers to develop and apply their competences is crucial for maintaining both motivation and high standards in the school education profession. However, many teachers across Europe claim to struggle to have access to effective forms of Continued Professional Development (CPD) coupled with the numerous demands already made on their work. Onsite (face to face) courses with opportunities for peer learning remain popular but are not time or financially cost-effective in reaching a large number of teachers. By exploring the pedagogical model of the online courses of the European Commission's 'Teacher Academy', this article discusses how an effective, collaborative approach to online CPD can be developed as a way of addressing both teacher and school education system needs.

Keywords: e-learning, teacher, CPD, peer-learning, pedagogy, MOOCs

\section{Introduction}

Evidence from the OECD Teaching and Learning International Survey (OECD, 2019) shows that many teachers in OECD countries struggle to access and benefit from continuous professional development (CPD), with very few, if any, improvements registered over the last decade (OECD, 2009; 2014). The question beckons, what needs to 
Hertz, B., Grainger Clemson, H., Tasic Hansen, D., Laurillard, D., Murray, M., Fernandes, L., Gilleran, A., Rojas Ruiz, D., \& Rutkauskiene, D.

A Pedagogical Model to Scale up Effective Teacher Professional Development - Findings from the Teacher Academy Initiative of the European Commission

change for teachers to access the CPD they require to address the challenges they face in their classrooms.

As a direct offer to teachers and school leaders across Europe, in 2016 the European Commission launched the Teacher Academy (TA) as part of the School Education Gateway platform (www.schooleducationgateway.eu), offering Massive Open Online Courses (MOOCs) for teachers. While targeting teachers directly, the Teacher Academy, was also designed to develop an understanding of how policy makers and teacher trainers can address some of the systemic challenges faced by teacher CPD provision in Europe.

For this purpose, this article explores the potential of the Teacher Academy initiative as a form of online CPD to address not only the barriers reported by teachers in accessing relevant CPD, but also allows for easy and cost-effective scalability, asking:

22. To what extent are teacher CPD MOOCs an effective CPD format that results in changes to teachers' practices and student outcomes?

23. To what extent are teacher CPD MOOCs a scalable mechanism that allow reach-out to teachers in need of more relevant CPD?

24. What instructional design features should teacher CPD MOOCs incorporate to engage teachers in an impactful way?

\section{Online Teacher CPD - An overview of recent literature}

Online CPD formats are inherently more flexible than onsite CPD, usually offering flexibility in when and where it is accessed, allowing teachers to benefit from it at times when it does not create conflicts with their usual work schedule, and without the costs and inconvenience of travel. Furthermore, teachers can access a wider selection of CPD, offered at regional, national or even international level, given that their participation does not depend on the geographic location of the offer.

\section{What is effective online teacher CPD?}

There is extensive research on what constitutes effective teacher CPD with general agreement that it should cover specific subject matter, allows engagement over time, and offers interactive experiences (Parsons et al., 2019). Furthermore "Successful [TPD] programmes [...] encourage the development of teachers' learning communities. A key strategy involves finding ways for teachers to share their expertise and experience systematically." (Schleicher, 2016; p.91). Similarly, Laurillard (Laurillard, 2016) argues that "unless teachers are the 'prime actors' in their own development, it will be impossible for them to keep up with the rapid changes in the environment, political, cultural, 
Hertz, B., Grainger Clemson, H., Tasic Hansen, D., Laurillard, D., Murray, M., Fernandes, L., Gilleran, A., Rojas Ruiz, D., \& Rutkauskiene, D.

\section{A Pedagogical Model to Scale up Effective Teacher Professional Development - Findings from the Teacher Academy Initiative of the European Commission}

economic and, especially, technological.” (p.3). Darling-Hammond et al. (2017) conducted a review of 35 methodologically rigorous studies that have demonstrated a positive link between teacher CPD and teaching practices and student outcomes. Based on this review they identify the following 7 elements of effective CPD:

\section{Content-focused,}

26. Incorporates active learning,

27. Supports teacher collaboration,

28. Offers models of effective practice,

29. Provides coaching support,

30. Provides time for reflection and feedback,

31. Sustained duration.

Effective CPD according to Darling-Hammond et al. should incorporate most of these 7 elements.

None of the elements mentioned above are restricted to face-to-face scenarios of CPD, so they should equally apply to online CPD. However, the literature does identify particular elements relevant for online CPD contexts to be effective for teachers, drawing in parts from the literature about online adult learning more generally. Powell and Bodur (2019) identify six design and implementation features which online teacher CPD should integrate, based on a review of the literature focussing on online adult learning as well as online teacher CPD: (a) relevancy of addressing teachers' learning needs, (b) usefulness to solve problems regarding teaching practice, (c) interaction and collaboration to generate engagement, (d) authentic tasks and activities which reflect teacher practice, (e) reflection to help contextualize new information, (f) understanding of the "intersectionality of technology, content, pedagogy, and learners”.

\section{Teacher CPD MOOCs}

MOOCs have become a common online learning format since the early 2010s. While MOOCs originally were meant to offer free education to those most in need, it quickly transpired that those making most use of MOOCs were highly educated professionals (Ho et al., 2014). Rather than using MOOCs as a format for undergraduate education as originally envisioned, they were quickly becoming a format for professional development.

Interestingly, many participants of MOOCs, regardless of the MOOC topic, are teachers. A large-scale study covering 68 MOOCs from Harvard and MIT revealed that almost 39\% of those enrolled identified as current or previous teachers (Ho et al., 2015). Similar results 
Hertz, B., Grainger Clemson, H., Tasic Hansen, D., Laurillard, D., Murray, M., Fernandes, L., Gilleran, A., Rojas Ruiz, D., \& Rutkauskiene, D.

\section{A Pedagogical Model to Scale up Effective Teacher Professional Development - Findings from the Teacher Academy Initiative of the European Commission}

were obtained in Europe where 10-25\% of all learners on non-teacher PD MOOCs were teachers (Castaño-Muñoz, Kalz, Kreijns, \& Punie, 2018). More so, a survey of 11 MIT MOOCs showed that despite only $4.5 \%$ of enrolees being teachers $22.4 \%$ of all discussion forum comments were made by teachers (Seaton, Coleman, Daries, \& Chuang, 2015) suggesting that teachers actively engaged and contributed to the course communities established as part of the MOOCs.

While there is an increasing number of teacher CPD MOOCs on general MOOC platforms (such as Coursera, Edx, Futurelearn), as well as MOOC platforms focussing specifically on teacher CPD (such as Teacher Academy, European Schoolnet Academy, INTEF MOOCs, MOOC-Eds), research focussing on teacher CPD MOOCs is scarce, with no literature so far examining systematically their effectiveness in achieving changes to teachers' practices or student outcomes.

Fyle (2013) was among the first to address the topic by evaluating the appropriateness of MOOCs for different types of teacher education. He concludes that MOOCs would only be an appropriate format for certain types of teacher education and more useful for experienced teachers than those at the start of their career. Furthermore, he portends that MOOC designs suitable for teacher CPD would have to incorporate "sophisticated online forums and other technology-oriented social structures and features that would support effective forms of socialconstructivist learning” (Fyle, 201; p.6).

Jobe et al. (2014) addressed the topic indirectly with a concept paper exploring the potential of using general MOOCs for teacher professional development, including considerations about MOOC design for teacher CPD. Their conclusion suggests that there is great potential for MOOCs as teacher CPD as long as MOOCs are recognised, validated, and accredited by teacher professional development providers and they should be designed with a focus on collaboration and connections between peers, more along the lines of the Connectivist MOOC (cMOOC) variant than the Transmissive MOOC (xMOOC) variant.

Koutsodimou and Jimoyiannis (2015) report positive findings from offering a teacher CPD MOOC in Greece, achieving a much higher completion rate than other MOOCs as well as highly positive feedback from teachers about their participation and impact on professional practice. Their investigation also focussed on specific design elements of their MOOC, concluding that a balance between structure (following the xMOOC approach) and openness (following the cMOOC approach) is required to enhance the outcomes of MOOCs for teacher CPD. 
Hertz, B., Grainger Clemson, H., Tasic Hansen, D., Laurillard, D., Murray, M., Fernandes, L., Gilleran, A., Rojas Ruiz, D., \& Rutkauskiene, D.

A Pedagogical Model to Scale up Effective Teacher Professional Development - Findings from the Teacher Academy Initiative of the European Commission

Laurillard (2016) investigated whether MOOCs could function as co-learning models of teacher CPD, particularly focussing on their applicability in emerging economies. Her findings - based on the results of a teacher CPD MOOC addressing the use of ICT in primary education - indicate that it is possible to use MOOCs effectively as teacher CPD as the MOOC format "fits well with the objective of supporting effective co-learning for professionals, who appreciate this form of high-quality learning, value each other's experience and knowledge and are willing to share their experiences to learn together" (Laurillard, 2016; p.13).

Castaño-Muñoz et al. (2018) looked at the profile of participants of teacher CPD MOOCs offered by the Spanish Ministry of Education, finding that MOOCs have become an alternative channel for teacher CPD in Spain but remain in their infancy with significant parts of the teacher population not benefitting from their offer. They conclude that awareness needs to be raised in particular amongst female primary school teacher and that formal recognition could significantly bolster the standing of MOOCs.

Misra (2018) offers the most comprehensive summary on the topic of MOOCs for teacher CPD so far, synthesising not just research on the topic but also blog posts and newspaper articles. He concludes that there is substantial untapped potential for using MOOCs as teacher CPD and suggests six actions that would allow a wider use in the teaching profession.

\section{The Teacher Academy - How an effective, collaborative approach to online CPD was designed}

The Teacher Academy offers MOOCs for teachers that are designed around 6 specific pedagogical principles which to a significant degree correspond with the features identified in the literature about effective online teacher CPD and in particular teacher CPD MOOCs:

32. Facilitating peer exchange: a sense of European co-design is cultivated in the courses which supports teachers to respect ownership and expertise of participants and facilitates innovation from a process of mutual curiosity and collective reflections.

33. Community building: TA courses purposefully integrate activities which do not necessarily focus on the course topic but only on developing a trusting and supportive environment - similar to ice-breakers or the opportunity for informal exchanges during a coffee break as part of an onsite workshop.

34. Peer review: assessment and validation of learning on TA courses are provided in the context of peer review activities between teachers. Teachers engage in a process of peer review for their main course work that supports learning about learning, 
Hertz, B., Grainger Clemson, H., Tasic Hansen, D., Laurillard, D., Murray, M., Fernandes, L., Gilleran, A., Rojas Ruiz, D., \& Rutkauskiene, D.

A Pedagogical Model to Scale up Effective Teacher Professional Development - Findings from the Teacher Academy Initiative of the European Commission

learning about assessment, builds community, and validates and assesses their course work.

35. Content as trigger: TA courses contain varied content such as project and lesson observation videos, and teacher and expert interviews, as well as contributions from participants. Content is not primarily used as a tool of knowledge transmission, as would be the case in a more traditional MOOC, but rather as a trigger for reflection, sharing and exchange by participants.

36. Flexibility: TA courses try to minimise the restrictions set on course participants in regard to a course schedule. There is only one deadline, allowing teachers to move through the course to a certain degree at their own pace. All obligatory course activities are asynchronous and teachers are free to drop-in and -out of the courses, just focussing on specific modules.

37. Facilitating transfer to practice: A core feature of all TA courses is that they require participants to transfer their learning into a concrete course output, such as a lesson plan, that allows for easy implementation in their own classroom or school. Through the creation of context specific course outputs participants have the opportunity to reflect on what they have learnt, and to consider it and adapt as necessary for use in their own setting.

\section{To what extent are teacher CPD MOOCs an effective teacher CPD format that results in changes to teachers' practices?}

Evidence from the Teacher Academy shows that teacher CPD MOOCs have the potential to be an effective format for teachers. Teachers participating in TA courses have consistently reported over the last three years that they have already implemented elements introduced on TA courses in their practice, with more than $95 \%$ confirming this in the TA course evaluation surveys. All data in this and the following sections are based on the results of the pre- and post-course surveys administered by the TA as part of its courses. Participation to these surveys is optional for the participants and entirely anonymous. The respondents therefore do not fully represent the entire course participant cohorts. The data presented mostly originates from the summary evaluation report of 2018 with $n=3360$ for the pre-course surveys (53\% of the total number of users starting a course) and $n=764$ for the post-course surveys (28\% of the total number of users completing a course). Qualitative feedback from teachers further confirms the potential for impacting teachers' practice and perceptions.

Of course, this does not provide evidence as to the actual impact of participating in a TA course nor the effectiveness of CPD MOOCs in general. The evidence is limited to a small 
Hertz, B., Grainger Clemson, H., Tasic Hansen, D., Laurillard, D., Murray, M., Fernandes, L., Gilleran, A., Rojas Ruiz, D., \& Rutkauskiene, D.

A Pedagogical Model to Scale up Effective Teacher Professional Development - Findings from the Teacher Academy Initiative of the European Commission

subset of the course participants - those that have successfully completed a course and decide to complete the evaluation survey. Furthermore, the findings are based on selfreported impact. We do not know to what extent teachers actually change their practice in the classroom after participating in a TA course nor to what extent any such change would be sustainable over a longer period of time. And there is no evidence available that could claim that TA courses have any impact on student outcomes.

Regardless of these limitations, the available data and observations from the TA courses are in line with the tentative findings of the existing literature that indicate a potential for teacher CPD MOOCs. We therefore might say that there is an increasing amount of evidence to suggest that teacher CPD MOOCs can be an effective teacher CPD format.

\section{To what extent are teacher CPD MOOCs a scalable mechanism that allow reach-out to teachers in need of more relevant CPD?}

MOOCs by definition are scalable and compared to onsite courses or closed online courses TA course numbers are high, with course enrolments of 1000-4000 users, a starting percentage of 50-70\% (of those enrolled) and a completion rate of $25-45 \%$ (of those started). In that regard they can be considered a good mechanism to increase the offer of CPD to teachers. However, in order to benefit from MOOCs, teachers require not only digital competence but also self-regulated learning competence and in case of the TA courses English language competence. This makes MOOCs not the most accessible CPD format which requires a certain skill set and experience in order to benefit from. This is confirmed by the profile of the majority of teachers participating on TA courses - experienced teachers with on average 16-20 years of teaching behind them and $76 \%$ already having experience of participating in online CPD.

These results also correspond with the findings of Fyle who suggests that MOOCs are more suitable for experienced teachers (Fyle, 2013). And to a certain extent it also follows the findings of Castaño-Muñoz et al. who report that teachers of ages 40-49 were overrepresented in Spanish teacher CPD MOOCs, indicating that they already had substantial teaching experience (2018). Furthermore, Castaño-Muñoz et al. find that teachers participating in Spanish teacher CPD MOOCs had a lower need for training in ICT skills than the overall Spanish teacher population, suggesting that MOOCs are less suited to those with lower ICT skills or digital competence overall.

While teacher CPD MOOCs can be a mechanism to make more CPD available to teachers, they cannot be the only solution to address the need for more CPD from teachers. More needs to be done to make MOOCs more accessible to all teacher profiles while at the same 
Hertz, B., Grainger Clemson, H., Tasic Hansen, D., Laurillard, D., Murray, M., Fernandes, L., Gilleran, A., Rojas Ruiz, D., \& Rutkauskiene, D.

A Pedagogical Model to Scale up Effective Teacher Professional Development - Findings from the Teacher Academy Initiative of the European Commission

time it is necessary to ensure teachers competences are developed so as to be able to benefit from CPD MOOCs and other online CPD formats. Blended approaches which make use of the online provision of a CPD MOOC with an onsite support infrastructure or workshop programme could be a way to support and reach more teachers.

\section{What instructional design features should teacher CPD MOOCs incorporate to engage teachers in an impactful way?}

While it has not been possible to determine the impact of the separate components of the TA instructional design, quantitative and qualitative data from course participants suggests that the design succeeds in creating a flexible learning environment which stimulates reflection, sharing of experience, discussion and transfer to practice.

$99 \%$ of respondents to the course evaluation surveys rate the structure of courses positively. Views on the video content, the main course activity of a course output with subsequent peer review, and the sharing of ideas and reflections as being useful for professional learning all receive above $90 \%$ positive ratings. Also reported by over $90 \%$ of participants by the time they complete the evaluation survey is that they have already implemented some elements from the course in their professional practice; they will use the tools, ideas and examples presented on the course in their everyday teaching practice; and that they have gained practical ideas on how they can improve their professional practice.

These findings correspond to those of Koutsodimou and Jimoyiannis who also received highly positive feedback from the course participants of their MOOC which was designed in a similar way to the TA courses (2015). The TA instructional design also follows to a significant extent their recommendation of a compromise between connectivist (cMOOC) and transmissive (xMOOC) design features. While focussing on establishing connections between participants, TA courses nevertheless operate from a centralised learning platform that is designed around course content.

$71 \%$ of respondents report that they remain in contact with other course participants after the conclusion of the course, which also suggests that some form of meaningful community building is taking place with useful connections between participants being created, consistent with Laurillard's findings on the usefulness of MOOC environments for professional co-learning (2016). Furthermore, the TA course design through its use of web 2.0 tools such as Tricider or Padlet as well as its strategic use of social media and chat environments, implements to a certain extent the "technology-oriented social structures and features that would support effective forms of social-constructivist learning" as advocated by Fyle (2013; p.6). 
Hertz, B., Grainger Clemson, H., Tasic Hansen, D., Laurillard, D., Murray, M., Fernandes, L., Gilleran, A., Rojas Ruiz, D., \& Rutkauskiene, D.

\section{A Pedagogical Model to Scale up Effective Teacher Professional Development - Findings from the Teacher Academy Initiative of the European Commission}

While we cannot conclude anything about the general teacher population from the results of the TA course evaluation surveys, data from these surveys show on the one hand a strong approval for the instructional design used and on the other hand that participants are reporting an impact from their course participation. Accordingly, we can say that for those that successfully participate in the TA courses the instructional design implemented seems to work very well.

\section{Conclusions}

Finding ways how to offer more support to teachers is paramount for addressing some of the main challenges faced by our education systems today. Continuous professional development is recognised as way to effectively support teachers. This paper has therefore explored the potential of MOOCs as a mechanism to reduce the barriers teachers face in accessing relevant CPD and at the same time scaling up the offer of CPD in an effective and efficient way.

By means of outlining the experiences and evaluation data of the TA courses and surveying the available literature, the paper has contributed insights and data to the still limited literature on the topic of teacher CPD MOOCs. It is clear from the findings that MOOCs have significant potential as an effective CPD format that allows for a degree of scalability. The instructional design of the TA courses shows that MOOCs can function along the principles of effective online CPD as defined in the literature and feedback data from participants suggests that the instructional design is highly appreciated by teachers and leads to changes in teachers' practice.

However, scalability, while possible, remains limited when using the instructional design presented. Teachers' need for digital competence and self-regulated learning competence, as well as English language competence in the case of the TA, in order to gain value from CPD MOOCs, means that there will be many teachers who are left out, not yet in a position to benefit from this CPD format.

Furthermore, the findings presented in the available literature and in this paper are not representative and do not offer a systematic investigation into the effectiveness of CPD MOOCs generally. More, and more systematic and longer-term research addressing the research questions in this paper is therefore required. 
Hertz, B., Grainger Clemson, H., Tasic Hansen, D., Laurillard, D., Murray, M., Fernandes, L., Gilleran, A., Rojas Ruiz, D., \& Rutkauskiene, D.

A Pedagogical Model to Scale up Effective Teacher Professional Development - Findings from the Teacher Academy Initiative of the European Commission

\section{References}

Castaño-Muñoz, J., Kalz, M., Kreijns, K., \& Punie, Y. (2018). Who is taking MOOCs for teachers' professional development on the use of ICT? A cross-sectional study from Spain. Technology, Pedagogy and Education, 27(5), 607-624.

Darling-Hammond, L., Hyler, M. E., \& Gardner, M. (2017). Effective Teacher Professional Development.

Fyle, C. (2013). Teacher Education MOOCs for Developing World Contexts: Issues and Design Considerations. Paper presented at the Sixth International Conference of MIT's Learning International Networks Consortium (LINC).

Ho, A.D., Chuang, I., Coleman, C., Whitehill, J., Northcutt, C., Williams, J. J., Hansen, J., Lopez, G., \& Peterson, R. (2015). HarvardX and MITx: Two years of massive open online courses - Fall 2012-Summer 2014. HarvardX Working Paper, 10, 1-37.

Ho, A. D., Reich, J., Nesterko, S., Seaton, D. T., Mullaney, T., Waldo, J., \& Chuang, I. (2014). HarvardX and MITx: The first year of open online courses - Fall 2012-Summer 2013. HarvardX and MITx Working Paper, 1.

Jobe, W., Östlund, C., \& Svensson, L. (2014). MOOCs for Professional Teacher Development. Proceedings of the Society for Information Technology \& Teacher Education International Conference, 1580-1586.

Koutsodimou, K., \& Jimoyiannis, A. (2015, November). MOOCs for teacher professional development: investigating views and perceptions of the participants. Paper presented at the $8^{\text {th }}$ International Conference of Education, Research and Innovation - ICERI2015, Seville, Spain.

Laurillard, D. (2016). The educational problem that MOOCs could solve: Professional development for teachers of disadvantaged students. Research in Learning Technology, 24(1), 29369.

Misra, P. K. (2018). MOOCs for Teacher Professional Development: Reflections and Suggested Actions. Open Praxis, 10(1), 67.

OECD. (2009). Creating Effective Teaching and Learning Environments. In Talis.

OECD. (2014). TALIS 2013 results: an international perspective on teaching and learning. In TALIS.

OECD. (2019). TALIS 2018 Results (Volume I). Paris: OECD. 
Hertz, B., Grainger Clemson, H., Tasic Hansen, D., Laurillard, D., Murray, M., Fernandes, L., Gilleran, A., Rojas Ruiz, D., \& Rutkauskiene, D.

A Pedagogical Model to Scale up Effective Teacher Professional Development - Findings from the Teacher Academy Initiative of the European Commission

Parsons, S. A., Hutchison, A. C., Hall, L. A., Parsons, A. W., Ives, S. T., \& Leggett, A. B. (2019). U.S. teachers' perceptions of online professional development. Teaching and Teacher Education: An International Journal of Research and Studies, 82(1), 33-42.

Powell, C. G., \& Bodur, Y. (2019). Teachers' perceptions of an online professional development experience: Implications for a design and implementation framework. Teaching and Teacher Education, 77, 19-30.

Schleicher, A. (2016). Teaching Excellence through Professional Learning and Policy Reform.

Seaton, D., Coleman, C., Daries, J., \& Chuang, I. (2015). Enrollment in MITx MOOCs: Are We Educating Educators? 